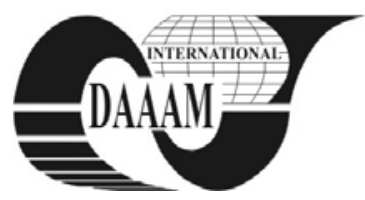

Annals of DAAAM for 2011 \& Proceedings of the 22nd International DAAAM Symposium, Volume 22, No. 1, ISSN 1726-9679 ISBN 978-3-901509-83-4, Editor B. Katalinic, Published by DAAAM International, Vienna, Austria, EU, 2011 Make Harmony between Technology and Nature, and Your Mind will Fly Free as a Bird Annals \& Proceedings of DAAAM International 2011

\title{
PROACTIVE APPROACH DURING DESING AND OPTIMIZATION OF PRODUCTION SYSTEM
}

\author{
MILLER, A[ntonin]; BURES, M[arek] \& SIMON, M[ichal]
}

\begin{abstract}
The current situation on world markets puts substantive competitive pressure on manufacturing companies. The enterprises in developing countries have their advantage in considerable amount of cheap labor. The enterprises in western countries have to take the advantage of longterm experience and modern technologies. One type of modern technologies is the use of the concept and software tools of digital factory. This paper is focused on creating and optimizing the layout and ergonomics analysis of individual workplaces. The issues of layout design and workplace ergonomics are mutually interconnected and they have to be dealth as a whole. Since nowadays the majority of companies do not have stable production program, the competitive advantage is sustained by proactive approach towards optimizing the layout and workplace ergonomics, thus before the problem occurs

Key words: production system, ergonomics, layout, proactive approach, sustainable development
\end{abstract}

\section{INTRODUCTION}

If a company wants to be nowadays competitively efficient, it has to have fully functional production system. The layout of this production system is one of the steps for its effective functioning. The solution has to be derived from the smallest elements (workplaces) and, by their grouping, the overall production system layout can be defined. These elements have to be analyzed, whether they function effectively, not even as an individual element, but also as a component affecting the whole network. Ergonomics plays an indisputable role when designing or optimizing workplaces. (Philips, 1997)

The computer market is nowadays overstocked with various software applications which ensure this collaboration across business units. We call them digital business tools. These software applications are used for digitalization and simulation of real production system and for linking the work of a designer, production engineer and industrial engineer. The problem is the motivation of these people; they have to be persuaded to effectively take an advantage of the applications which have a considerable potential.

In this paper, there will be introduced synergy effects resulting from the close cooperation and mutual interconnection of the work of an ergonom and a production designer when optimizing the production system.

\subsection{Current approach towards design and optimalization of layout}

Currently, the majority of projects on optimizing and designing production system layout are effectuated because of requested savings in production system, increasing output of production system and the change of production system.

When designing and optimizing production system layout, the current situation is analyzed at first and 2D or 3D model with material, personnel and information flows is enregistered.

Subsequently, the model is adjusted to minimize production spaces, to optimize material, personnel and information flows, to balance workplace capacities, to minimalize transportation output and to maximize production system output. (Harris et al., 2003) Key indicators for comparing individual designs and choice of suitable version are transportation output, spendings on creation, running of production system and production system output. (Srajer et al., 2010)

\subsection{Current approach towards optimization of workplace ergonomics}

Nowadays, optimization of workplace ergonomics is done predominantly when a problem at workplace is discovered. Usually, this problem is either the occurrence of worker's health complications or the lack of observance of safety rules. The analysis includes the creation of 3D workplace model on which work procedure is simulated and worker's physiologic load is examined by various analyses. Simultaneously, the external influences on workplace are monitored. After a thorough analysis, the whole workplace is evaluated and the changes of current situation are proposed. The model of this modified workplace is checked afterwards.

\subsection{Current approach towards collaboration}

Thus, it is obvious that projects concerning layout and workplace ergonomics are handled separately and with different goals. Optimization of production system layout monitors overall system output. (Smalley, 2004) On the other hand, optimalization of workplace ergonomics is aimed at worker's health, safety and performance at workplace.

It is evident that collaboration of individual subjects is crucial. From this perspective, it is important to apply proactive approach while solving optimization tasks or production system designs. Only through this approach we are able to avoid inefficient wasting associated with consequent production changes, which causes higher costs, apart from a lost profit caused by malfunction of existing production system. The current reactive approach to designing or optimizing production system is predestinated to disappear. It is proactive approach that industrial engineers, production engineers and designers will have to take into account. Close collaboration of individual company departments is inevitable.

\section{CASE STUDY}

Proactive approach while dealing with production system layout and workplace ergonomics has been tested in a company engaged in job-order manufacture of shower cabins. In the production, manufacturing and assembly operations are represented by the same share, thus human factor is highly used. The main task was to optimize production system in order to reduce overall transportation output, manipulation distances and, additionally, to optimize individual workplaces according to ergonomics and safety rules. To solve such a complex task, complex methods are used. The key factor was 3D model in virtual reality (Fig. 2), which was created on basis of original state of production system, both for layout optimization and for workplace ergonomics optimization. Optimising workplace ergonomics has been solved at first. The workplaces, which 
were properly designed from an ergonomic point of view, were subsequently linked with regard to the principles of suitable material and personnel flows. (Bures \& Černý, 2008)

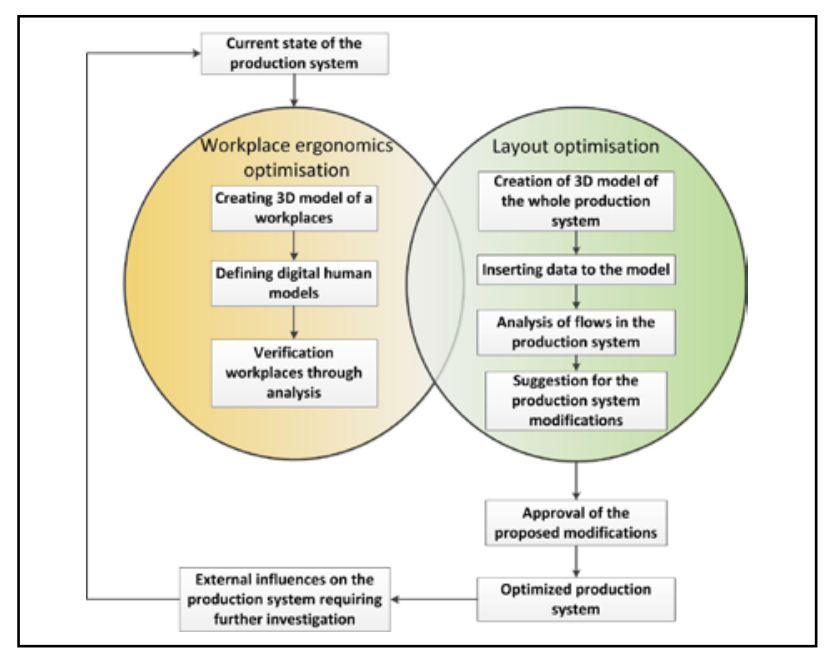

Fig. 1.Production system optimization schema

\subsection{Optimising workplace ergonomics}

To test the workplaces from an ergonomic point of view, it has been created previously mentioned 3D models of selected workplaces. These models were identical copies of a real situation, which was extremely important with regard to high predicative potential of the results. Moreover, to verify the ergonomics parameters of a particular worker or a group of workers, digital human model (Fig. 2) has been used. This model represents an authentic biomechanical copy of a real person and with its aid identical situations at workplace can be simulated. Compliance with ergonomic principles has been checked by using well known and widespread analysis such as RULA (McAtemney \& Corlett, 1993), NIOSH (Waterset et al., 1993) and others (Ciriello \& Snook, 1991).

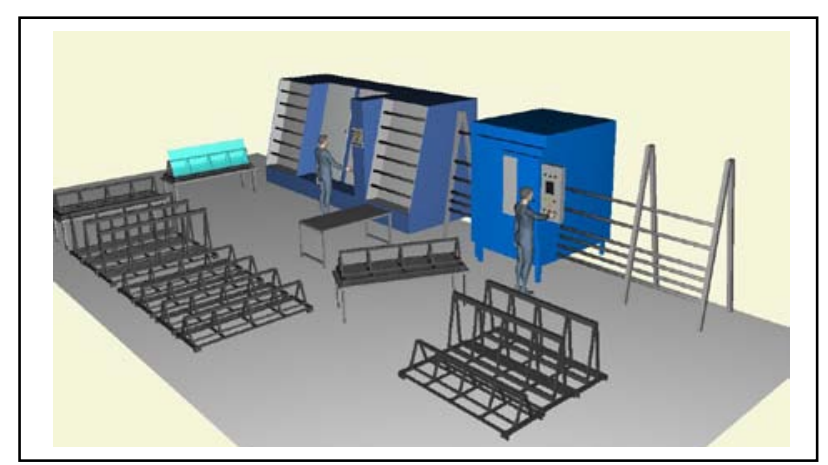

Fig. 2. 3D model of a workplace

\subsection{Optimising layout}

Complex 3D model, which was created by merging models of individual ergonomically adjusted workplaces, was the basis for the subsequent implementation of the layout optimization. Firstly, the model was filled with data from production processes, planned production volume, time exigeance of processes, etc., in order to correspond the reality. Not all information can be obtained from company information system, and therefore the remaining data was collected by asking workers directly in the production.

The crucial part was the analysis of material, personnel and information flows in the production. During the analysis, it has been used the methods of Sankey diagram, I-D diagram and on their basis, problematic areas of production system has been defined. The results of previous analysis and the results of ergonomics analysis of individual workplaces has been interconnected, and subsequently, overall production system layout has been created, or, more precisely, the changes in the arrangement and size of workplaces. This activity functioned also as a feedback; the linking of individual workplaces to the whole production system has been monitored. Especially, the links to logistic system (inputs and outputs from workplaces) has been monitored together with the question whether individual workplaces do not have negative impact on each other. The last part was the creation of two designs of new production system layout, which were subsequently examined from the point of workability difficultness and costs on the modifications of existing system.

\section{CONCLUSION}

The objective of the paper is to highlight on a practical example the benefits of collaboration among individual project activities. Thanks to the use of all previously mentioned methods, experience and simultaneous work of the designer and ergonom; we were able to save within main optimization criteria $5 \%$ of manipulation distance and $9 \%$ of manipulation output. Of course, several secondary benefits exist that are difficult to measure and to prevent. For example reducing absence associated with a reduction of physical loading, enhancement of the productivity due to pleasant working environment and comfortable working position or reducing production operation by decreasing movements without added value.

\section{ACKNOWLEDGEMENTS}

This paper was supported by Internal Grant Agency of University of West Bohemia. Project No. SGS-2010-065 "Multidisciplinary Design Optimization and Operation of production system in digital factory environment.

\section{REFERENCES}

Bures, M.; Černý, Z. (2008). System approach for production organism design, Proceedings of the 12th international research/expert conference TMT, Istanbul, Turkey, ISBN 978-9958-617-41-6

Ciriello, V. M.; Snook, S. H. (1991). The design of manual handling tasks: revised tables of maximum acceptable weights and forces. Ergonomics, 34, 1197-1213

Harris, R.; Harris, Ch. \& Wilson, E. (2003). Making materials flow: a lean material-handling guide for operations, production-control, and engineering professionals, Lean Enterprise Institute, ISBN 0974182494, Cambridge

McAtamney, L.; Corlett E. N. (1993). RULA - A survey method for the investigation of work-related upper limb disorders. Applied Ergonomics, 24, 91-99

Philips, J. E. (1997). Manufacturing plant layou: Fundamentals and Fine Points of Optimum Facility Design, Society of Manufacturing Engineers, ISBN 0-87263-484-1, Dearborn Michigan

Smalley, A. (2004). Creating level pull: a lean productionsystem improvement guide for production-control, operations, and engineering professionals,Lean Enterprise Institute, ISBN 0974322504, Cambridge

Srajer, V.; Miller, A. \& Simon, M. (2010). Importance of the proposal layout for increasing competitiveness enterprise, Annals of DAAAM for 2010 \& Proceedings of The 21th international DAAAM symposium, 20-23rd October 2010, Zadar, Croatia, ISSN 1726-9679, ISBN 978-3-901509-735, Katalinic, B. (Ed.), pp. 0787-0788, Published by DAAAM International Vienna, Vienna

Waters, T. R.; Putz-Anderson, V., Garg, A. \& Fine, L. J. (1993). Revised NIOSH equation for the design and evaluation of manual lifting tasks. Ergonomics, 36, 749-776 